\title{
Kekuatan Hukum Covernote Melalui Pemberian Kredit Bank dengan Jaminan Hak Tanggungan Apabila Terjadi Kredit Macet
}

\author{
Henny Pratiwi Pinatih ${ }^{1}$ \\ ${ }^{1}$ Program Studi Magister (S2) Kenotariatan Fakultas Hukum Universitas Udayana, \\ E-mail: hennypratiwipinatih@gmail.com
}

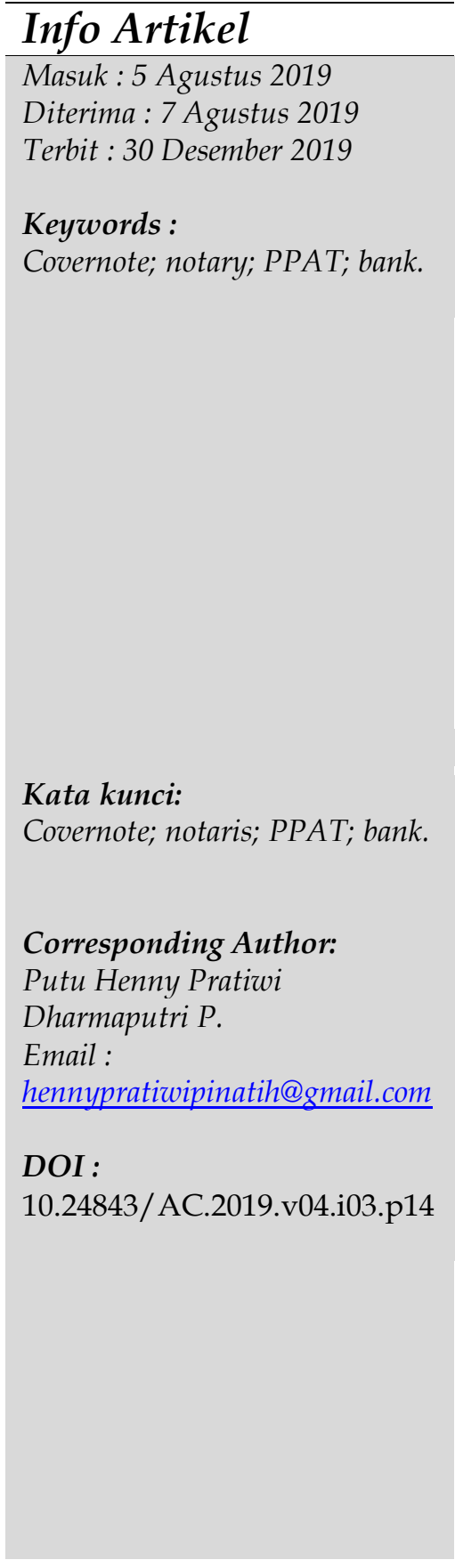

\begin{abstract}
The use of covernote Notary / PPAT is commonly used in the practice of granting loans given by banks to debtors. Covernote is not an authentic deed, so that in the event of a bad credit the bank becomes difficult to execute the guarantee. The problem that occurs is whether covernote can provide legal protection for the bank in the event of bad credit? and what is the legal strength of covernote in the event of bad credit but the authentic Deed has not been issued and the insurance has not yet been installed? This study moved from normative legal research to the norm of emptiness because in the Act of Notary Position, Banking Law, Underwriting Law and Government Regulation on PPAT did not regulate the existence of covernote. The results of the study can be seen that the vacuum of norms due to the existence of covernote resulted in covernote not being able to provide a legal protection in the event of bad credit. The legal strength of covernote in the event of bad credit does not have the power of executorial law, this is because covernote is not a notary / PPAT legal product stipulated in the relevant laws and regulations.
\end{abstract}

Abstrak
Penggunaan covernote Notaris/PPAT umum diperguakan saat
memberikan kredit yang diberikan dari kreditur kepada debitur.
Covernote bukanlah akta otentik, sehingga apabila terjadi kredit
macet pihak bank menjadi mengalami kesulitan untuk melakukan
eksekusi jaminan. Permasalahan yang terjadi yaitu apakah
covernote bisa memberikan perlindungan hukum untuk bank
jika terjadi kredit macet? dan Bagaimanakah kekuatan hukum
covernote apabila terjadi kredit macet namun Akta otentik belum
diterbitkan dan jaminn belum terpasang hak tanggungan?
Penelitian ini beranjak dari penelitian hukum normatif
kekosongan norma karena dalam Undang-Undang Jabatan
Notaris, Undang-Undang Perbankan, Undang-Undang Hak
Tanggungan maupun Peraturan Pemerintah tentang PPAT
tidak mengatur menegnai keberadaan covernote. Hasil peneitian
dapat diketahui bahwa Kekosongan norma terkat keberadaan
covernote mengakibatkan covernote tidak dapat memberikan
suatu perlindungan hukum apabila terjadi kredit macet.
Kekuatan hukum covernote apabila terjadi kredit macet tidaklah
memiliki kekuatan hukum eksekutorial, hal ini disebabkan karena
covernote bukanlah produk hukum notaris/PPAT sebagaimana
tercantum pada perundan-undangan terkait.




\section{Pendahuluan}

Notaris merupakan seseorang yang mempunyai jabatan dan memiliki kewenangan dalam mengeluarkan akta autentik. Jabatan ini adalah suatu jabatan yang memiliki kewenangan yang harus dipertanggung jawabkan. Undang-undang yang ada kaitannya dengan seorang notaris terdapat dalam undang-undang jabatan notaris ( UUJN ) yang telah mengalami perubahan yaitu UU Nomor 2 tahun 2004 atas perubahan UU Nomor 30 tahun 2004. Di dalam pasal 1 disebutkan bahwa notaris mempunyai wewenangan untuk memrancang akta autentik. Dalam suatu jabatan seorang notaris tidak hanya melaksanakan perintah dari UU melainkan juga membatu para pihak yang berkepentingan dalam cakupan kewajiban seorang notaris. Dasar hukum seorang notaris dalam menjalankan tugasnya adalah notaris mempunyai kewenangan atas semua tindakan, persyaratan, dan penentuan yang diatur pada UU atau sesroang yang bersangkutan untuk dicantumkan pada akta. Ada beberapa kewenangan lain dari seorang notaris dalam pasal ini yaitu menjamin waktu pembuatan, grosse, salinan dan kutipan akta. ${ }^{1}$

Pemberian suatu kredit dari bank kepada nasabah selaku debitur tentunya untuk memberikan jaminan kepastian hukum atas pemberian kredit tersebut maka diperlukan peranan dari Notaris dan PPAT terkait akta-akta otentik dan pembebanan jaminan kredit tersebut terutama terkait jaminan hak atas tanah adalah melalui pembuatan akta pember ian hak tanggungan (HT) dan juga akta pemberian kuasa membebankan HT.

Notaris dan PPAT yang mempunyai hubungan kerja dari bank terkait dengan pembuatan akta otentik dan pendaftaran jaminan kredit maka notaris/PPAT berwenang membuat akta yang dapat memperlihatkan bahwa adanya perbuatan hukum dari bank (kreditur) dengan nasabah (debitur) dihadapan notaris/PPAT, sehingga adanya akta yang dicetak oleh Notaris/PPAT adalah hal yang sangat penting bagi para pihak untuk dapat melindungi kepentingannya.

Pemberian kredit dari bank sebagai kreditur kepada debiturnya dalam kaitannya dengan dokumen yang dipergunakan untuk penjaminan maka sudah menjadi suatu kebiasaan dan kesepakatan yang pada umumnya dilaksanakan antara perbankan dengan Notaris/PPAT yang memiliki fungsi untuk mengatasi dari kurang lengkapnya atau belum terselesaikannya dokumen penjaminan yang diurus oleh notaris/PPAT yang mengakibatkan notaris /PPAT mengeluarkan covernote yang menjelaskan keadaan pada saat penandatanganan dokumen-dokumen kredit hingga pemberian objek anggunan seperti sertipikat hak atas tanah yang diserahkan pemberi HT pada bank merupakan sesuatu yang ada kaitannya dengan pencairan kredit untuk debiturnya. Terkait dengn hal tersebut mengakibatkan pentingnya suatu penerbitan Covernote Notaris/PPAT pada saat pencairan kredit yang bisa menjadi landasan sebagai suatu alat bukti untuk Bank agar mencairkan kredit untuk debiturnya. Kemitraan antara Notaris/PPAT dan Bank merupakan hubungan hukum (law binding) yang memiliki tanggung-jawab yang mengikat antara kedua belah pihak dikarenakan Covernote Notaris/PPAT menjadi bagian tak terpisahkan oleh cara

\footnotetext{
${ }^{1}$ Sujanayasa, I. K., Ibrahim, R., \& Ariawan, I. G. K. kedudukan saksi Instrumentair. Acta Comitas.hal.284
} 
terbentuknya peristawa hukum yaitu Perjanjian Kredit dan Perjanjian pemasangan HT atas agunan, sehingga Covernote Notaris/PPAT yang Bank terima memiliki fungsi menjadi alat bukti hukum yang kuat, dan juga berisi pernyataan Notaris/PPAT bahwa dokumen legal yang diminta oleh Bank telah ditandangani oleh Debitur serta pemberian janji-janji Notaris/PPAT untuk membereskan dokumen legal/akta sesuai pada waktu yang telah disepakati. ${ }^{2}$

Covernote lebih dikenal dengan istilah surat keterangan, surat ini digunakan untuk menerangkan atau menyatakan bahwa suatu akta dalam suatu proses pengurusan di kantor notaris/PPAT yang bersangkutan. UUJNP, UU Perbankan, UUHT, maupun PP Nomor 37 Thn 1998 tidak diatur mengenai keberadaan dari covernote tersebut, padahal Surat keterangan atau covernte merupakan salah satu produk dari Notaris dan PPAT sehingga dapat dikatakan produk covernote ini bukan wewenang Notaris dan PPAT namun tidak dilarang untuk dibuat oleh notaries dan PPAT karena kebutuhan di masyarakat. Permasalahan dapat timbul apabila pada saat kredit sudah dicairkan kepada debitur dan ternyata agunan tidak diterima oleh kreditor. Permasalahan yang dapat terjadi yaitu notaris / PPAT telah menerbitkan covernote untuk penyelesaian pembebanan HT terhadap jaminan kredit yang dicairkan pihak bank namun ternyata terjadi permasalahan yang mengakibatkan sertipikat hak milik berupa tanah yang dipergunakan sebagai jaminan tersebut tidak dapat dibebankan oleh hak tanggungan kemudian terjadi kredit macet yang mengakibatkan bank menjadi kesulitan untuk melaksanakan eksekusi atas objek jaminan tersebut. Berdasarkan latar belakang masalah tersebut maka penulisan ini dibuat dengan judul "KEKUATAN HUKUM COVERNOTE MELALUI PEMBERIAN KREDIT OLEH BANK DENGAN JAMINAN HAK TANGGUNGAN APABILA TERJADI KREDIT MACET." Masalah- masalah yang akan dibahas yaitu : apakah covernote dapat menyampaikan perlindungan hukum untuk pihak bank bila menjadi kredit macet? dan Bagaimanakah kekuatan hukum covernote apabila terjadi kredit macet namun Akta otentik belum diterbitkan dan jaminn belum terpasang hak tanggungan?

Maksud Penelitian secara umum untuk menumbuhkan pemikiran hukum terkhusus hukum kenotariatan tentang covernote dalam cakupan perjanjian kredit bank. Melainkan yang menjadi maksud kusus ialah agar bisa menguraikan dan menganalisa dalam hal perlindungan hukum covernote bagi bank dan Untuk dapat lebih mengerti dan melaksanakan kegiatan selanjutnya tentang kekuatan hukum covernote apabila terjadi kredit macet namun jaminan kredit belum terpasang HT.

\section{Metode Penelitian}

Adapun jenis penelitian yang dipakai disini adalah jenis penelitian hukum normatif, yang dikerjakan melalui penelitian hukum dari peraturan perundangan-undangan dan dari segi refrensi yang ada kaitannya dengan permasalahan. ${ }^{3}$ Penelitian ini berawal dari kekosongan norma terkait dengan kekuatan hukum covernote notaris dalam perjanjian kredit bank karena baik pada UUJN maupun UUJNP dan juga dalam UU Perbankan tidak adanya satupun pasal yang berisi aturan covernote notaris tersebut.

\footnotetext{
2 Shahrullah, R. S., \& Djufri, W. A. (2017). Tinjauan Yuridis Covernote Notaris/Ppat Terkait Pemasangan Hak Tanggungan Agunan Bank.hal.151

3Soerjono Soekanto dan Sri Mamudji, (2007), Penelitian Hukum Normatif: Suatu Tinjauan Singkat, PT. Raja Grafindo Persada, Jakarta, hal. 13.
} 
Karya ilmiah ini memakai pendekatan analitis, konsep, dan perundang-undangan yang akan membahas masalah dalam karya ilmiah ini. Sumber bahan hukum yang dipakai ialah melalui penelitian terhadap data sekunder, yaitu data yang didapat dari hasil penelitian terhadap kepustakaan (Library Research). Sumber bahan hukum yang dipakai ialah bahan hukum primer yang bersumber dari peraturan perundangundangan, bahan hukum sekunder yang yang terdiri dari literature-literatur, bukubuku, makalah, dokumen-dokumen yang berkaitan dengan covernote. Mengenai teknis analisis bahan hukum yang diterapkan dalam penelitian ini diawali dengan pengumpulan dan sitematisir bahan-bahan hukum yang diperoleh untuk kemudian dianalisis. Analisis dilakukan guna untuk menyelesaikan permasalahan yang ada dengan menggambarkan yang menjadi masalah, menjelaskan masalah, mengkaji masalah, dan memberikan argumentasi dari hasil evaluasi sehingga didapat kesimpulan mengenai persoalan yang dibahas pada penelitian ini.

\section{Hasil dan Pembahasan}

Perjanjian kredit menjadi suatu perjanjian perjanjian utama yang wajib dilaksanakan ketika keduanya yaitu kreditur dan debitur telah sepakat untuk memberikan dan menggunakan fasilitas kredit. Umumnya suatu perjanjian kredit biasanya disertakan pula adanya jaminan kebendaan yang kemudian dituangkan dalam suatu perjanjian jaminan yang memiliki hak kebendaan dan bersifat assecoir (tambahan) seperti jaminan fidusia dn Hak Tanggungan. ${ }^{4}$

Perjanjian kredit dan perjanjian hak tanggungan dibuat untuk mengikat hubungan hukum diantara pihak kreditur dengan debitur, menjamin telah terjadinya kesepakatan antara kreditur dengan debitur dalam melakukan hutang piutang. Setelah dibuatnya perjanjian tersebut baik dengan dibawah tangan oleh pihak bank ataupun yang dilakukan dengan akta otentik oleh notaris, terlebih dahulu bank akan meminta kepada Notaris untuk menerbitkan covernote. Adapun covernote ini dibuat oleh Notaris/PPAT sebgai pernyataaan kemampuan dari Notaris/PPAT untuk melakukan proses pembebanan jaminan atas kredit apa yang bank berikan yang memuat diantaranya telah ditandatangani suatu perrjanjian antara bank dengan debitur, telah dberikan jaminann agunan dari yang berhutang pada bank sebagai kreditur, telah ditandatanganinya akta surat kuasa membebankan HT atau akta pemberian HT dimana seluruhnya masih dalam proses melalui Notaris/PPAT rekanan bank yang bersangkutan. ${ }^{5}$

Covernote terdiri dari dua suku kata bahasa Inggris, yaitu cover and note, cover memiliki arti tutup, note merupakan suatu catatan, sehingga covernote diartikan ke dalam bahasa Indonesia menjadi suatu tanda catatan penutup. Covernote adalah istilah dalam kenotariatan yang merupakan sebuah surat yang berisi keterangan yang dikeluarkan oleh Notaris terhadap pernyataannya terkait dengan telah ditandatanganinya aktaakta yang berkaitan dengan suatu perbuatan hukum dari notaris yanbg berisi cap dan tandatangan dari notarius bersangkutan. Pernyataan seperti itu bisa diberikan dengan tegas, tapi juga menyangkut ke dalam satu atau beberapa perilaku. Kecuali diberitau

\footnotetext{
${ }^{4}$ Indra jaya, Rudi dan Ikmasari Ika, (2016), Kedudukann Aktaa izyn Roya HT sebagai Pengganti Sertifikat Hak Tanggungan Yang Hilang, Visimedia, Jakarta, hal.1

${ }^{5}$ Sanjaya, I. D. M. D. tanggung jawab seorang notaris pada penerbtan covernotes kredit. Riau Law Journal, 1(2), hal.180-204.183
} 
berbeda, pemberitauan mencakup maslah pemberitauan keterangan yang berbeda, bisa diberitaukan dalam bentuk yang bagaimanapun juga atau mencakup dalam beberapa perilaku.

Proses penyerahan kredit hingga pendaftaran HT dimulai melalui pemprosesan Surat Order dari bank yang diserahkan kepada Notaris. Surat order digunakan agar keberadaan pembuatan penyerahan kredit menjadi aman jika notaris tersebut berhalangan saat menemui bank dan notaris mempunyai kepercayaan dari bank hingga bisa di keluarkannya covernote ${ }^{6}$

Untuk Pemberian hak tanggungan hingga adanya pembebanan HT semestinya dimulai dengan janji untuk menyerahkan HT sebagai pelunasan hutang yang dicantumkan dalam perjanjian yang di pisah dari perjanjian utang tersebut dan penyerahan HT wajib dilaksankan dengan akta Pemberian HT yang dilaksanakan dimuka PPAT. Pemberian HTtersebut harus di catat dikantor Pertanahan. Btas waktu pendaftarannya adalah minimal 7 hari setelah akta Pemberian HT ditandatangani dan diberi nomor dan tanggal.

Covernote pada umumnya dikategorikan sebagai suatu bentuk kesepakatan yang ada karena perjanjiann tidak karena hal tersebut telah diatur dalam UU atau bisa jg disebut sebagaii kesepakatan yang ada oleh suatu perjanjian karena berasal dari hukum kebiasaan. Tercatat dalam Pasal 1233 KUHper yaitu tiap perikatan dibuat secara persetujuan, maupun karena Undang-undang. Covernote yang lahir berdasarkan suatu kebiasaan yang dilakukan secara berulang-ulang untuk suatu kepentingan pencairan kredit di bidang perbankan sebagai suatu sumber formil. Bila kebiasaan tertentu diindahkan oleh masayrakat, dan kebiasaan itu terus diperbuat, oleh karena itu munculah sesuatu kebiasaan hukum yang karena habit dipandang sebegai hukum.

Tanpa adanya covernote pihak bank belum dapat mencairkan kredit yang dipinjam oleh debitur karena pihak bank terlebih dahulu harus menerima kesanggupan dari pihak Notaris/PPAT untuk menjalankan isi dari covernote ialah bisa memberikan kedudukan preferensi bagi seorang bank terhadap kredit yangmana telah diberikannya kepada seorang debitur. Keberadaan covernote notaris/PPAT dalam penyeraahan kredit perbankan menjadikan suatuhal kebiasaan yang dilakukan, tapi didalam peraturan perundang-undangan baik dari UUJN, UUJNP, UU Perbankan maupun UU HT tiada dapat ditemui ketentuan yang mengatur mengenai keberadaan covernote sehingga diperlukan pengaturan konsekuensi hukumnya untuk menyampaikan kepastiann hukum yng bisa memberikan perlindungn hukm untuk yang memberi serta yang menerima kredit dan juga orang yang ada kaitanya untuk mendapat perlindungan dari lembaga jaminan yang kokoh dan bisa memberitau kepastian hukm untuk seluruh orang yang ada kepentingannya.

Terkait kebutuhan covernote dalam pemberian kredit di bidang perbankan, maka kewenangan dari notaris/PPAT untuk mengeluarkan covernote tidak diatur dalam UU. Merujuk pada yang dimaksud oleh pasal 15 UUJN mengatur seorang notaris mempunyai hak merancang akta autentik, mengesahkan ttd, membukukan surat dibawah tangan, membuat risalah lelang dan memberikan penyuluhan hukum.

${ }^{6}$ Utama, I. M. B. D. P., Setiabudhi, I. K. R., Putra, W., \& Bagus, I. Penggunaan Surat Order dalam Proses Pengikatan Agunan Kredit Berupa Hak Tanggungan. Acta Comitas, 3..hal.1 
Kewenangan notaris untuk menerbitkan covernote tidak ada diatur dalam UUJN jadi menimbulkan terjadinya kekosongan norma terkait diterbitkannya covernote oleh notaris. Covernote Notaris adalah pondasi atas kepercayaan pada kesanggupan Notaris untuk menyelesaikan semua dokume dan akta yang terkait dengan pemberian kredit hingga pembebanan jaminan. Covernote bukanlah suatu akta otentik walaupun covernote dikeluarkan oleh Notaris/PPAT. Covernote diterbitkan hanya untuk keperluan pemberian kredit di bidang perbankan dan lembaga pembiayaan pada umumnya. Kekosongan norma terkat keberadaan covernote mengakibatkan covernote tidak dapat memberikan suatu perlindungan hukum apabila terjadi kredit macet. Hal ini diakibatkan covernote hanyalah kesanggupan dari notaris/PPAT untuk menyelesaikan hal-hal yang tercantum di covernote tersebut dan covernote bukanlah akta otentik sehingga tidak dapat menjadi perlindungan hukum untuk suatu bank jika kredit menjadi macet. Apabila terjadi permasalahan yang menimbulkan kredit menjadi macet namun pembebanan jaminan belum dapat terlaksana, dalam hal ini maka covernote tidaklah dapat dijadikan dasar bagi bank untuk serta merta melakukan lelang atas jaminan kredit tersebut. Perlindungan hukum bagi bank selaku kreditur didapatkan setelah terbitnya sertipikat hak tanggungan yang memebrikan kedudukan preferensi atau kedudukan untuk diutamakan apabila terjadi kredit macet sehingga kreditur pemegang sertipikat hak tanggungan secara hukum telah mendpatkan perlindungan karena memiliki kekuatan untuk didahului pelunasan kreditnya karena telah memegang jaminan yang sudah terdaftar secara hukum dengan adanya sertipikat hak tanggungan.

Penyerahan kredit yang diperbuat Bank untuk lembaga keuangan, mewajibkan memberikan perlindungan hukum untuk penerima ataupun pemberi kredit. Pemberian kredit tentunya akan mengandung resiko terkait dengan pengembalian kredit tersebut dalam jarak waktu antara pencairan kredit dengan pmbayaran lagi oleh debitur. ${ }^{7}$ Maka dari itulah untuk pemberian kredit dari Bank diwajibkan ada jaminanya, hal ini diperlukan supaya kredit yang telah dicairkan bank pada debitur mendapat kepastian pengembaliannya dari pihak debitur.

Kredit menurut ketentuan Pasal 1 angka 11 UU Perbankan dapat diketahui ialah "kredit merupakan penyediaan uang atau tagihan yang bisa disamakan dengan itu, berdasarkanpersetujuan atau persetujuan meminjam antar Bank dengan pihak lain yang mewajibkan peminjam untuk melunasihutang setelah jangka waktudengan pemberian bunga." Arti kredit menurut ketentuan pasaal tersebut begitu luas mengenai ruanglingkup dan unsurunsur yangmana meliputi pengkreditan ini, sehingga penangananya juga wajib dilaksnakan secara hati-hati, sehingga proses pemberian kredit hingga analisa kredit tersebut dapat berjalan dengan baik. ${ }^{8}$

Kredit sebgai suatu pembiayaan yang beresiko maka dari itu pihak bank haruslah didasarkan pada pemikiran yang sehat dan berhati-hati. ${ }^{9}$ Kredit yang menjadi suatu kredit macet diakibatkan dari suatu keadaan debitur yang tidak lagi bisa membayar tepat pada waktunya. Keadaan itu dikatakan sebagai wanprestasi.

Terdapat beberapa persyaratan yang harus tercantum dalam suatu covernote agar

${ }^{7}$ Hasssanudin, (2010), Aspek-Aspek Hukum Pemberian Kredit Perbankan di Indonesia, PT Citra Aditya Bakti, Bandung, hal. 106.

${ }^{8}$ Djumhana, (2016), Hukum Perbankan Indonesia, PT Citra Aditya Bakti, Bandung, hal. 471.

9 RachmadiUsmn, (2010), Aspek-Aspek Hukum Perbankan Indonesia, PT. Gramedia Pustaka Utama, Jakarta, hal. 246 
covernote yang dibuat tersebut dapat berfungsi sebagaimana mestinya, adapun syarat dimaksud terdiri dari :

1. Covernote tersebut diterbitkan oleh pejabat yang berwenang yaitu notaris/ PPAT.

2. Adapun Minuta-minuta akta yang berkaitan dengan proses pembebanan suatujaminan dan juga surat-surat lain yang diperlukan untuk memproses pemasangan jaminan itu sudah ditandtangani dengan lengkap oleh semua pihak, saksi-saksi dan Notaris dan atau PPAT

3. penyerahan jaminann kredit dari debitur telah diserahkan kepada pihak bank untuk selanjutnya pihak bank melakukan penyerahan jaminan tersebut kepada notaris/PPAT untuk diproses pembebanan jaminannya.

4. Covernote memuat kapan sertipikat HT atau Fidusia bisa dapat di terima bank.

5. Notaris/PPAT memberi jamin bahwa sahnya sertifikat dengan sebelumnya melakukan pengecekan pada Kantor Badan Pertanahan bersangkutan untuk jaminan fidusia dilengkapi dengan surat pernyataan bahwa BPKB adalah benarbenar milik nasabah dan belum dilakukan balik nama atas BPKB tersebut.

6. Jaminan tidak ada biaya lain

7. Pernyataan bahwa apabila sertifikat HT atau Fidusia telah terbit maka Notaris dan atau PPAT akan menyerahkan sertipikat jaminan tersebut kepada pihak bank. ${ }^{10}$

Adapun covernote yang dibuat oleh notaris dan atau PPAT pada umumnya mencantumkan beberapa hal sebagai berikut:

1. Dokumen pengikatan yang ditandatangani oleh para pihak, kelengkapan dokumen dan surat-surat yang dibutuhkan serta tahap untuk diurusnya.

2. Ksanggupan dri notaris dan atau PPAT untuk nukti hak yang asli serta pengikatan kdengan bank bila proses jaminan sampai terbit sertipikat jaminan usai diselesaikam.

3. Lamanya waktu pengurusan dari semenjak minuta akta ditandatangani hingga proses pembebanan jaminan terselesaikan.

PPAT/Notaris dalam mengeluarkan covernote yang dapat berlaku sebagai surat keterangan telah terjadinya tindakan hukum terkait hukum jaminan hak tanggungan, covernote dapat dipergunakan untuk menjamin telah ditandatanganinya berbeagai akta sebagai contoh fidusia, gadai, dan hipotik. Tetapi sekarang akan dibahas didalam karya ilmiah ini hanya HT, karena dalam dikeluarkannya kredit dari bank, pihak bank cenderung memprioritaskan kredit yang berupa tanah sebagai jaminannya yangmana diikat dengan HT, karena nilai ttanah akan semakin meningkat. Maka dari itu karena itulah hnya jaminan yang dengan HT yang memerlukan covernote karena HT masih proses rooya, pembalikan nama, masih hakmilik adat, atau masih dalam pemprosesan pendftaran tanah diBadan Pertanahan, karena itulah agar kredit bisa cepat keluar walau surattanah HT masih dalam pemprosesan maka dikeluarkannlah covernote sebagai pgangan dari pihak bank karena jminan yang menjadi HT sedang

${ }^{10}$ Mukti, A. M. (2018). Peran notaies dalam memberikan covernte pada perjanjiian kredit antar bank dengn jaminan HT (Studi Kasus di Kantor Notaris-PPAT Dr. I Gde Mastra, SH., MM., M. Kn Kota Malang) (Doctoral dissertation, University of Muhammadiyah Malang).hal.48 
pemprosessan oleh Notaris/PPAT yang megeluarkan covernote tersebut. ${ }^{11}$

Suatu Covernote secara proses bukanlah suatu bagian melalui pemprosesan dibuatnya sertifikat HT yang berakhir dengan melakukan pendaftran HT di BPN tempat beradanya jaminan. Walau seperti itu, covernote sering menjadi ganti atas kurangnya bukti jminan semantara bagi bank dalam dikeluarkannya kredit. Dalam proses HT belum selesai karena masih dalam proses pengurusan pemasangan hak tanggungan pada Badan Pertanahan, maka keberadaan Covernote adalah bagian dua proses peristiwa hukum yakni perjanjian pinjaman kredit dan jaminan HT.12

Covernote bisa menjadi suatu bukti tertulis oleh pihak yang merasa dirugikan atas pembuatan covernote tersebut atas tidak dilaksanakannya janji atau kesanggupan atas perbuatan hukum tertentu sebagaimana tercantum didalam isi covernote yang di buat oleh Notaris dan atau PPAT bersangkutan. Suatu covernotes tidak bisa menggntikan fungsi sertipikat HT sebagai jaminan dari suatu kredit yang sudah dicairkan oleh baank kepada nasabh debitur.

Adapun yang akanmrnjadi konsekuensi yuridis dari dibuatnya suatu covernote dalam pemberian kredit oleh pihak bank yaitu covernote tidaklah sebuah akta auutentik, covernote adalah sebuah surat keterangn yang dibuatt oleh notaris dan atau PPAT dalam memproseskan pendaftaran jaminan baik berupa HT, maupun fidusia, yang mengakibatkan keberadaan covernote ini mnjadi tidaklah memiliiki kekuatan pembuktian yang sempurna. Keberadaan suatu Covernote tetap memilki kekuatn pmbuktian selama covernote ini tidak ditolak oleh pmbuatnya yaitu oleh notaries atau PPAT. Dibuatnya covernote oleh notaris/PPAT merupakan murni bentuk kepercayaan dan adanya suatu ikatan moral berdasarkan hukum kebiasaan dari kreditur terhadap notaris atau PPAT sebagai pejabat umum bersifat netral, mandiri dan tidak memihak dalam membantu masyarakat untuk menunjang dan menciptakan transaksi bisnis yang efisien. ${ }^{13}$

Notaris dalam mengeluarkan suatu Covenote ada suatu konsekuensi hokum terkait dikeluarkannya covernote tersebut, jika dalam proses pembuatan sertifikat HT terjadi masalah maka dalam penyelesaiannya, yang terjadi adanya kendala-kendala seperti dalam proses pemecahan seritikat, balik nama, ataupun kendala lain yang dalam proses penerbitan sertifikan HT dapat menjadi permasalahan dikemudian hari.

Permasalahan dapat terjadi yang mengakibatkan kredit macet namun jaminan belum dibebani hak tanggungan maupun fidusia mengakibatkan kesulitan melakukan eksekusi oleh bank atas objek jamiinan tersebut. Dalam hal inilah tentunya dpat diketahui bahwa covernote dalam perjanjian kredit hanya berfungsi sebgai surat pengantar yang diberikan oleh Notaris/PPAT adalah agar bank sebagai instansi yang memerlukan mendapatkan jaminan bahwa berkas yang dibtuhkan oleh bank ialah sesunggunya benar dalam prosess pengurusan sehingga terdapat kepercayaan yang dibangun diantara pihak bank dengan notaris, bank dengan kliennya dan bank dengn instansi yang bersangkutan.

11 Budiyono, S. (2018). Prlaksanna praktek covrnote yang dibuat oleh noatries/PPAT sebagaisyarat pcairan kredit.(Doctoral dissertation, Fakultas Hukum UNISSULA). Hal. 16

12 Hermawan, E. (2017). Kekuatan hkm covrnote dan tanggungjawab noatris dalam dm pembuatn cornote sbgai produk hkm yang tiadk diatur dalam undang-undang(Doctoral dissertation, Fakultas Hukum UNISSULA).hal.7

${ }^{13}$ Charani,D.W. covrnote dalm prjnjian kredit dengan jaminan HT.hal.4 
Kekuatan hukum covernote apabila terjadi kredit macet tidaklah memiliki kekuatan hukum eksekutorial, hal ini disebabkan karena covernote bukanlah produk hukum notaris/PPAT yang diatur dalam peraturan perundangan yang ada kaitannya. Kekosongan norma ini mengakibatkan covernote menjadi tidaklah memiliiki kekuatn hukum untuk memberikannya perlindungan hukum untuk pihak bank maupun pihak nasabah debitur, namun dengan terjadinya kredit macet dalam hal ini tentunta pihak bank lah yang mengalami kerugian.

Covernote berdasarkan uraian diatas dapat diketahui bukanlah akta autentik, covernote bukan produk notaris yang dalam UU sebagi produk resmi Notaris / PPAT dan tidak ada dalam UU hal kewenangan Notaris, untuk membuat covernote. Kewenangan notaris ialah membuat akta yang ditegaskan UU, akta seharusnya bentuknya dibuat sesuai perundang-undangan dan dibuat oleh didepan pejabat yang seharusnya, jika covernote tidak mempunyai kriteria akta autentik tetapi merupakan suratketerangan yng dikeluarkannysa oleh Notaris.

\section{Kesimpulan}

Covernote bukanlah suatu akta otentik walaupun covernote dikeluarkan oleh Notaris/PPAT. Covernote diterbitkan hanya untuk keperluan pemberian kredit di bidang perbankan dan lembaga pembiayaan pada umumnya. Kekosongan norma terkait keberadaan covernote mengakibatkan covernote tidak dapat memberikan suatu perlindungan hukum jika terjadi kredit macet. Hal ini diakibatkan covernote hanyalah kesanggupan dari notaris/PPAT untuk menyelesaikan hal-hal yang tercantum di covernote tersebut dan covernote bukanlah akta otentik sehingga tidak dapat menjadi perlindungan hukum bagi pihak bank jika terjadinya kredit yang macet. Apabila terjadi permasalahan yang menimbulkan kredit menjadi macet namun pembebanan jaminan belum dapat terlaksana, dalam hal ini maka covernote tidaklah dapat dijadikan dasar bagi bank untuk serta merta melakukan lelang atas jaminan kredit tersebut. Perlindungan hukum bagi bank selaku kreditur didapatkan setelah terbitnya sertipikat hak tanggungan.

Kekuatan hukum covernote apabila terjadi kredit macet tidaklah memiliki kekuatan hukum eksekutorial, hal ini disebabkan karena covernote bukanlah produk hukum notaris/ PPAT yang ada dalam peraturan perundangan yang mengenai itu. Kekosongan norma ini mengakibatkan covernote menjadi tidak mempunyai kekuatan hukum untuk mmberikan perlindungan hukum untuk pihak bank atau nasabah debitur.

Saaran yang dapat penulis diberikan ke dalalam penelitian ini yaitu hendaknya untuk para Notaris-notaris dan atau PPAT selalu berhati-hati dalam menerbitkan covernote agar nantinya pendaftaran covernote tidak mengalami kendala dikemudian hari yang mengakibatkan sertipikat menjadi tidak dapat terpasang hak tanggungan maupun terpasang fidusia. Pemerintahlajh dalm hal ini pembuat undangundang hendaknya mempertimbangkan untuk mengatur keberadaan covernote dalam peraturan perudangundangan yang ada kaitannya dengan tugas, fungsi dan kewenangan baik notaris maupun PPAT sehingga nantinya covernote ini mendapatkan kekuatan hukum nya. 


\section{Daftar Pustaka}

Buku

Hassanudin Rahman, (2010), Aspek-Aspek Hukum Pemberian Kredit Perbankan di Indonesia, PT Citra Aditya Bakti, Bandung

Indra jaya, Rudi dan Ikmasari Ika, (2016), Kedudukan Akta izin Roya Hak Tanggungan sebagai Pengganti Sertifikat Hak Tanggungan Yang Hilang, Visimedia, Jakarta

Rachmadi Usman, (2010), Aspek-Aspek Hukum Perbankan di Indonesia, PT. Gramedia Pustaka Utama, Jakarta

Muhammad Djumhana, (2016), Hukum Perbankan di Indonesia, PT Citra Aditya Bakti, Bandung

Soerjono Soekanto dan Sri Mamudji, (2007), Penelitian Hukum Normatif: Suatu Tinjauan Singkat, PT. Raja Grafindo Persada, Jakarta

\section{Jurnal}

Budiyono, S. (2018). PELAKSANAAN PRATIK COVERNOTE YANG DIBUAT OLEH NOTARIS/PPAT SEBAGAI SYARAT PENCAIRAN KREDIT DI PT. BANK MAYAPADA INTERNASIONAL, Tbk CABANG JEPARA (Doctoral dissertation, Fakultas Hukum UNISSULA). 16

CHAIRANI, D. W. COVERNOTE DALAM PERJANJIAN KREDIT DENGAN JAMINAN HAK TANGGUNGAN.

Hermawan, E. (2017). KEKUATAN HUKUM COVERNOTE SERTA TANGGUNGJAWAB NOTARIS TERHADAP PEMBUATAN COVERNOTE SEBAGAI PRODUK HUKUM YANG TIDAK DIATUR DALAM UNDANGUNDANG JABATAN NOTARIS (Doctoral dissertation, Fakultas Hukum UNISSULA).7

Mukti, A. M. (2018). PERAN NOTARIS DALAM PEMBERIAN COVERNOTE PADA PERJANJIAN KREDIT ANTARA BANK DENGAN NASABAH DENGAN JAMINAN HAK TANGGUNGAN (Studi Kasus di Kantor Notaris-PPAT Dr. I Gde Mastra, SH., MM., M. Kn Kota Malang) (Doctoral dissertation, University of Muhammadiyah Malang). 48

Sanjaya, I. D. M. D. TANGGUNG JAWAB HUKUM NOTARIS TERHADAP PENERBITAN COVERNOTE DALAM PEMBERIAN KREDIT. Riau Law Journal, 1(2), 180-204.183

Shahrullah, R. S., \& Djufri, W. A. (2017). Tinjauan Yuridis Covernote Notaris/Ppat Terkait Pemasangan Hak Tanggungan Agunan Bank.151

Sujanayasa, I. K., Ibrahim, R., \& Ariawan, I. G. K. KEDUDUKAN SAKSI INSTRUMENTAIR AKTA NOTARIS DALAM KAITANNYA DENGAN PASAL 16 AYAT (1) UNDANG-UNDANG NOMOR 30 TAHUN 2004 TENTANG JABATAN NOTARIS. Acta Comitas.284

Utama, I. M. B. D. P., Setiabudhi, I. K. R., Putra, W., \& Bagus, I. Pengaturan Penggunaan Surat Order dalam Proses Pengikatan Agunan Kredit Berupa Hak Tanggungan. Acta Comitas, $3 . .1$ 